\title{
Pyogenic Liver Abscess: Prospective Evaluation Of USG Guided Percutaneous Therapeutic Aspiration
}

\author{
Dr. Pranab Kumar Ghosh ${ }^{1}$, Dr. Nilay Mandal ${ }^{2}$, Dr. Jagonmay Majhi ${ }^{2}$, Dr. Mintu \\ Mohan Nandi ${ }^{2}$, Dr. Shib Shankar Kuiri ${ }^{3}$, Dr. Gautam Ghosh ${ }^{4}$ Dr.Tapati Mandal ${ }^{5}$ \\ ${ }^{I}$ Senior Resident, Department Of Surgery, R.G.Kar Medical College, Kolkata, India \\ ${ }^{2}$ Asst.Professsor,Department Of Surgery, B.S.Medical College, Bankura, India \\ ${ }^{3}$ R.M.O Cum Clinical Tutor, Department Of Surgery, B.S.Medical College, Bankura, India \\ ${ }^{4}$ Professor, Department Of Surgery, R.G.Kar Medical College, Kolkata, India \\ ${ }^{5}$ Demonstrator, Department Of Microbiology, Maldah Medical college,Maldah,India
}

\begin{abstract}
:
Background: Pyogenic liver abscess (PLA) has been a condition of high mortality, improving over recent decades with combined antibiotic and percutaneous drainage Percutaneous drainage is currently the treatment of choice in liver abscess. Percutaneous needle aspiration(PNA) as an alternative to continuous percutaneous catheter drainage in combination with systemic antibiotics for the treatment of PLA has never been popular. Aims\&Objectives: To evaluate the role of ultrasound (USG) guided percutaneous needle aspiration along with systemic antibiotics in the management of PLA. Material And Methods: From January 2012 to July 2013,50 patients (45 male; 15 female; most common age range 40-50 years; mean age 44.34 years) with PLAs (mean diameter $6.52 \pm 1.8 \mathrm{~cm}$; range 4.8 - 9cm) underwent PNA with ultrasound (USG) guidance and antibiotic therapy. Complete pus removal from each abscess was attempted with 18 gauge thin-walled trocar needles with USG guidance. If necessary, PNA was repeated every 3 day. Results: The percentage of abscesses requiring one, two, three and more sessions of aspiration was $50 \%, 30 \%, 18 \%$ and $2 \%$ respectively. The success rate was unrelated to the largest size or number of abscess in the patient. Cure (normalization of clinical and laboratory parameters and resolution of hepatic lesions) was achieved in all patients (100\%).. Patients were hospitalized for 7-22 days (mean11 14.56 days) No patient needed imaging-guided percutaneous catheter drainage or open surgical. Neither complications nor deaths ensued. Recurrence of PLA was not observed in any patient during follow-up (6-12) months Conclusions: USG-guided PNA with antibiotic therapy in treatment for PLA is a safe, effective \& low-cost procedure. It should be considered as a first line alternative to catheter drainage. Our data suggest that a trial of percutaneous needle aspiration should always be undertaken before catheter drainage or surgery.
\end{abstract}

Keywords: Pyogenic Liver Abscess, Ultrasonography, Percutaneous Needle Aspiration

\section{Introduction}

Liver abscess was recognised in ancient times and through the centuries was invariably fatal. No progress was made until the seminal paper by Ochsner and colleagues in 1938[1]. They reported a $62 \%$ survival rate for patients undergoing surgical drainage. Combination of surgical drainage and antibiotics became standard treatment for the next four decades. Next landmark paper was in 1953 when McFadzean and coworkers[2] first reported on percutaneous drainage, which was successful in 14 patients without a death. Percutaneous drainage remained relatively unheralded for several decades until the mid 1980s, when reports of patients successfully treated by percutaneous drainage and antibiotics were published [3,4] ( Bertel et al , 1986 ; Gerzof et al , 1985). USG and CT allowed earlier and more definitive diagnosis followed by percutaneous procedures using these modalities for accurate drainage. Since then combined approach consisting of chemotherapy and image guided drainage is the preferred method The role of open operations in the treatment of pyogenic liver abscess is limited. . But controversies are arising regarding the mode of drainage procedure. Although percutaneous placement of an indwelling catheter is the method most widely preferred to drain liver abscesses, recent studies have shown therapeutic needle aspiration to be a simpler, less costly, and equally effective mode of treatment.[5] So, our study was an effort to establish the role of percutaneous needle aspiration as a therapeutic approach in management of pyogenic liver abscess.

\section{Materials And Methods:}

The study was conducted prospectively over a period of 1.5 years from January 2012 to July 2013 in the Department of General Surgery at Bankura Sammilani Medical College, a tertiary level teaching hospital. 50 Indoor patients who were admitted with Pyogenic Liver Abscess(PLA) and were treated with USG guided 
percutaneous needle aspiration(PNA) along with systemic antibiotics were included. The following patients were excluded: 1. Unwilling patients 2. Associated with co-morbid conditions ( Diabetes, malignancy, Cirrhosis, metabolic liver disease etc.) 3. Diagnostic dilemma- Hydatid Cyst, Haemangioma etc . 4. Coagulation disorders.

The patients in the study group were subjected to a) A complete physical examination including thorough examination of abdomen and chest following proper history. b) Specific Investigations including complete haemogram, liver function test, prothrombin time, blood for HbsAg, HIV, fasting and post prandial blood sugar, ultrasound of abdomen, chest $\mathrm{X}$ ray, microscopic examination and culture of aspirated pus. The patients were started emperical therapy with intravenous metronidazole and 3rd generation cephalosporin(Ceftriaxone).These patients were selected for percutaneous needle aspiration. Informed consents were taken from the patients explaining the complications of the procedures for which open surgical intervention might be needed. Coagulation factors were determined in all patients before the scheduled procedure to rule out any bleeding disorder.

The scheduled protocol was as follows: All patients would be treated with a single percutaneous needle aspiration of all abscess cavities in a single session. All percutaneous needle aspiration procedures were performed under sonographic guidance. The freehand technique was used because it does not have the limitation of attached needle guides, use of which necessitates that the needle be passed at a specific or fixed angle relative to the transducer. The freehand technique allows changes in the needle path. Local anesthesia was induced with $10 \mathrm{~mL}$ of lignocaine hydrochloride ( $2 \%$ ). Patients were asked about their pain during the procedure, in case they needed conscious sedation. After induction of local anesthesia, continuous real-time sonographic imaging was used to localize the abscess and to guide insertion of the needle. An I 8-gauge needle was advanced into the abscess cavity and the contents were aspirated in an attempt to completely evacuate the cavity. At first, deep lesions were punctured to avoid artifacts due to gas bubbles. Whenever possible, an intercostal approach was used for percutaneous needle aspiration. To prevent the spread of infection, needles were changed between aspirations. Aspirated pus was examined and microbiologic tests were performed to determine the causative organism. Once the laboratory results were available, antibiotics were changed on the basis of sensitivity tests. However, patients in whom pus culture findings were negative were continued on the same broad spectrum antibiotics.

The patients were examined daily for clinical improvement. Improvement in fever, chill and rigor, right hypochondriac pain, anorexia, malaise, nausea and vomiting were noted. Periodic-sonography and TLC were repeated every third day after aspiration to assess the cavity size and reponse until the patients were hospitalized. Outcome was assessed by:1. Relief of right hypochondriac pain(RHP) 2. Relief of fever 3 . Decreased intercostal tenderness 4. Resolution of liver abscess size ultrasonographically .5. Normalisation of leucocyte count.

Patients who did not improve clinically (subsidence of fever and local signs and symptoms) after the first aspiration and continued to have leukocytosis or showed refilling of the abscess cavity on follow-up sonography were subjected to further aspiration. Patients were discharged from the hospital when fever and clinical signs disappeared, total leucocyte count normalised, the dimensions of the abscess were reduced on ultrasonography, with advice of continuation of oral antibiotic for 2 weeks. Follow-up consisted of sonographic and clinical examinations of all patients, every month thereafter until complete resolution of the abscess were noted.

\section{Results And Analysis}

A total no of 50 patients were included in this study. 45 patient were male ( $90 \%$ of the patient) and 5 were females $(10 \%)$. Table no. 1 shows that in our study most of the patients were between the age group 40-50 years $(56 \%)$ and mean age of the patients was 44.34 years.

During admission 35(70\%) patients had fever , 47(94\%) patients had right hypochondriac pain(RHP), 31 patients $(62 \%)$ had anorexia and malaise, 14 patients $(28 \%)$ had icterus clinically, 18 patients $(36 \%)$ had nausea and or vomiting. Among 35 pts , $85 \%$ had history of chills and rigour. This is shown in Figure 01 . Overall, at the time of admission, four patients had one symptom, 17 patients had two symptoms, 13 patients had three symptoms, 11 patients had four symptoms, and only five with 5 symptoms. Ninety two percent patients presented with more than one associated symptoms. Among the patients who had only one clinical feature most of them presented with right hypochondriac pain(RHP). 


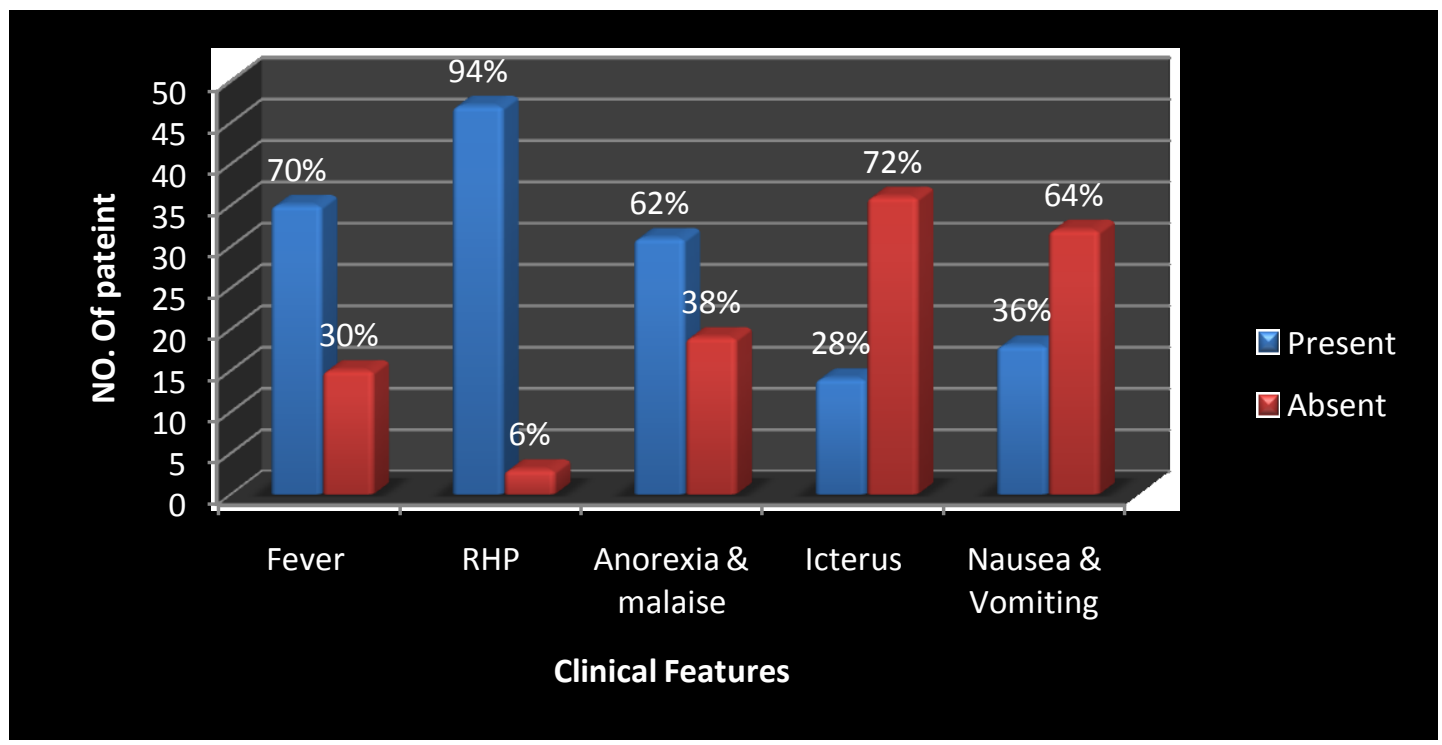

Figure 01: Distribution Of Patient According To Clinical Features

Table no [2] shows distribution of total leucocyte count during hospital admission. Most of the patients (60\%) have total count between 10001-15000, in 34\% cases it was 15001-2000.

In our study, 43 patients $(86 \%)$ had single abscess whereas $7(14 \%)$ patient had more than one abscess cavity. Right lobe was most commonly involved lobe. Figure 02 . Shows ninety four percent patients only right lobe was involved whereas in $4 \%$ patients left lobe was involved . only $2 \%$ cases both lobes were involved.

Table No.1. Distribution of patients according to age group

\begin{tabular}{|l|l|l|}
\hline Age group & No. of study subjects & Percentage \\
\hline $20-30 \mathrm{yr}$ & 3 & 6 \\
\hline $30-40 \mathrm{yr}$ & 07 & 14 \\
\hline $40-50 \mathrm{yr}$ & 28 & 56 \\
\hline$>50 \mathrm{yr}$ & 12 & 24 \\
\hline Total & 50 & 100 \\
\hline
\end{tabular}

Table No. 2:Total leukocyte count (TLC) among patients during admission.

\begin{tabular}{|l|l|l|}
\hline TLC & No. of patients & Percentage \\
\hline $5000-10000$ & 02 & 4 \\
\hline $10001-15000$ & 30 & 60 \\
\hline $15001-20000$ & 17 & 34 \\
\hline$>20000$ & 1 & 2 \\
\hline Total & 50 & 100 \\
\hline
\end{tabular}


Table No.3 shows size of abscess cavity during initial ultrasonography. In 34 patients (68\%) abscess cavity size were $5-8 \mathrm{~cm}$, in 8 patient $<5 \mathrm{~cm}$ and in 8 patient $>8 \mathrm{~cm}$. Smallest cavity size was $4.8 \mathrm{~cm}$ and largest one $9 \mathrm{~cm}$ with mean size $6.52 \pm 1.8 \mathrm{~cm}$.

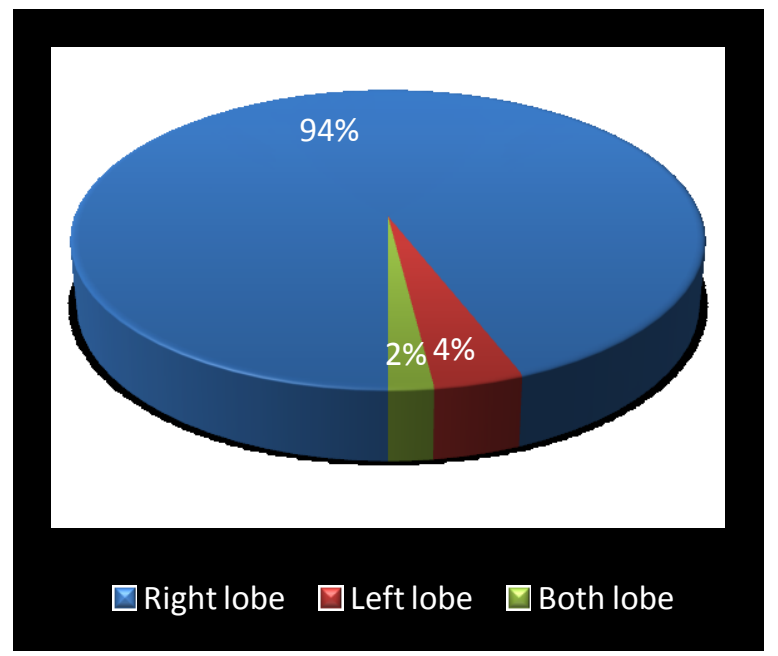

Figure 02 : Distribution Of Involvement Of Lobe

In our study, pus culture were positive in $40(80 \%)$ patients and negative in 10 patients $(20 \%)$ E.Coli was the most commonly isolated organism (40\% cases) followed by, staphylococcus $(24 \%)$ Kleibsiella $(10 \%$, ) and mixed organism $(06 \%)$.(This is shown in Table No. 4$)$

Table No.3: Size of abscess cavity in initial ultrasonography

\begin{tabular}{|l|l|l|}
\hline size & No. of study populations & Percentage \\
\hline$<5 \mathrm{~cm}$ & 08 & 16 \\
\hline $5-08 \mathrm{~cm}$ & 34 & 68 \\
\hline $08 \mathrm{~cm}$ & 08 & 16 \\
\hline Total & 50 & 100 \\
\hline
\end{tabular}

Table No.4: Distribution of patients according reports of pus culture

\begin{tabular}{|l|l|l|}
\hline Organism & No. of patients & Percentage \\
\hline E.Coli & 20 & 40 \\
\hline Kleibsiella & 5 & 10 \\
\hline Staphylococcus & 12 & 24 \\
\hline Anaerobes & 00 & 00 \\
\hline Mixed & 3 & 06 \\
\hline Negative & 10 & 20 \\
\hline Total & 50 & 100 \\
\hline
\end{tabular}


Figure 3. shows 25 patient $(50 \%)$ patients required single, 15 patient $(30 \%)$ required aspiration twice whereas $09(18 \%)$ patient thrice and only $1(2 \%)$ patient required four times aspirations. Our study shows needle aspiration effective in all cases. No.of aspiration were unrelated to no. or size of abscess cavity

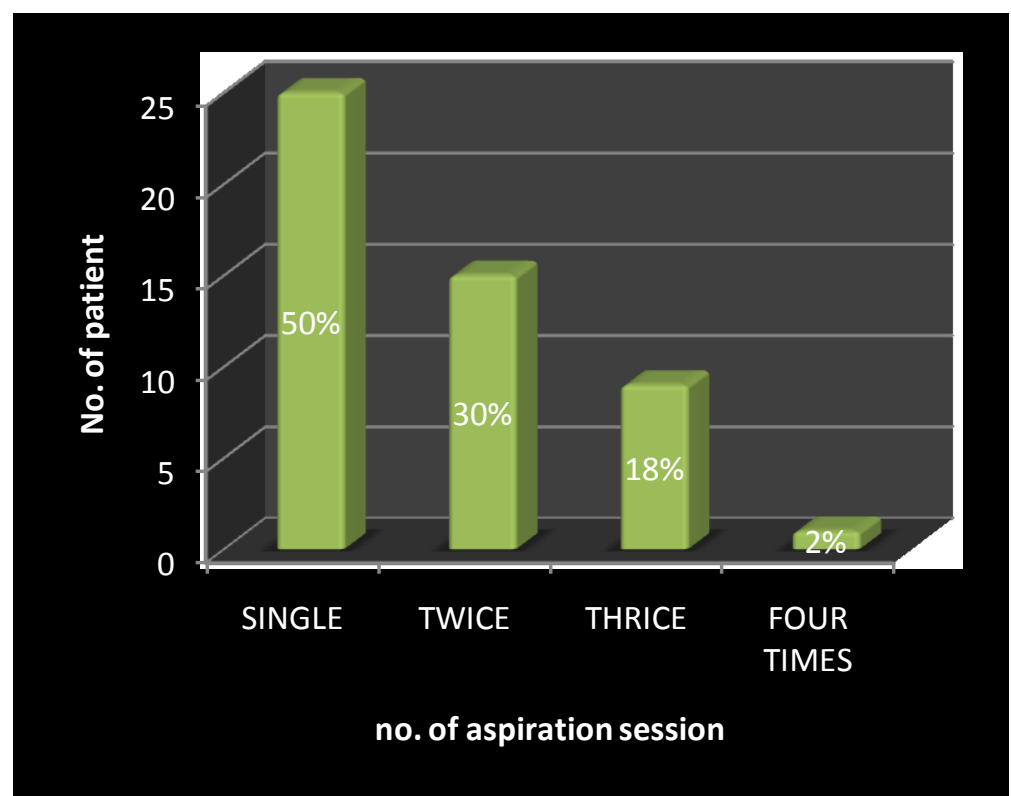

Figure 3 : Distribution Of Patients According To No. Of Aspiration Session

In our study, patient improved clinically within $6.24 \pm 4.02$ days (range 2 to 13 days) after first aspiration and total leucocyte count normalizes after mean of $7.8 \pm 5.04$ days(range3 to 15 days) after therapeutic aspiration.

Most of our patients (50\%) were discharged within 7 days, only $20 \%$ needed hospitalisation for more than 14 days. The patient were hospitalized for mean 11 days \pm 4.56 ( range 7 to 22 days). In our study there were no reports of procedue related complication as well as no reports of recurrence on follow up.

\section{Discussion}

In our study most of the patients were between the age group 40 - 50 years (56\%) and mean age of the patients was 44.34 years (Table no.1) Our study results simulates results of other studies. [6,7] Ninety percent of our patients were male and $10 \%$ female . So male : female ratio is $9: 1$. Reports in the literature show there is a male preponderance in a ratio ranging from 10:1 to $17: 1[8,9,10]$. The male preponderance may be due to high percentage of alcohol intake among males and less awareness among females to seek medical advice for illness. However small sample size may also be a cause.

Majority of our patients was suffering from fever (70\%) at the time of presentation (Figure No.01) and $85 \%$ of them got associated chill and rigor. In our study, $94 \%$ of the patients had right hypochondriac pain(RHP).RHP was most common presentation of our study. Although clinical presentation varies in different studies, our results were similar to Wilmot et al who in 1962 showed that $99 \%$ of the patients presented with abdominal pain and DeBakey and Oschner et all showed it $88.6 \%[11]$ but different from Barrio $\mathrm{J}$ et al who showed fever $(82.2 \%)$ was the most frequent clinical symptom.[12] Sixty two percent of our patients had anorexia and malaise(Figure No.01) . But no other study is available regarding this clinical feature except the one carried out by Onkar Singh et al in 2009.[13] Their study showed that 54\% of the patients had anorexia and malaise. Our study result is close to this one Only $28 \%$ patients of our study presented with jaundice. In 1987 Barnes et al in a study showed that $22 \%$ patients with pyogenic liver abscess had jaundice.[14] But the values obtained by Lodhi et al in Pakistan are different from previous studies, they observed that $43 \%$ patients with pyogenic liver abscess had jaundice[9]. Thirty six percent patients had nausea and or vomiting (Figure No.01). Our study result is similar to study by Barbara Alkofer and his colleagues [15]. But other study results are different. The study carried out by Oschner and DeBakey showed $22.7 \%$ patients presented with nausea and vomiting [11]. Ninety two percent patients presented with more than one associated symptoms. Among the patients who had only one clinical feature most of them presented with right hypochondriac pain.

Most of the patients $(60 \%)$ had leukocyte count ranging from 10001 to 15000 cells $/ \mathrm{mm} 3$, in $34 \%$ cases it was 15001-2000 (Table no 02). Earlier studies had reported the mean TLC to be 15000cells/mm3 with the range $7500 \mathrm{cells} / \mathrm{mm} 3$ to $25000 \mathrm{cells} / \mathrm{mm} 3$. [8] 
Majority of our patients (86\%) had single liver abscess cavity and $94 \%$ of our patients had their right lobe involved (Figure No 2).This finding is similar to other studies where solitary abscess and right lobe involvement were most commonly noted $[9,10,12,16,17,18]$

In our study $68 \%$ patients had abscess size between $5-8 \mathrm{~cm}$ with a mean of $6.5 \pm 1.8$ (Table 03).It was similar to other studies[6,15,17,19,20] In our study pus culture were positive in $80 \%$ patients with E.Coli in $40 \%$ cases, Kleibsiella in $10 \%$, staphylococcus in $24 \%$ and mixed organism in $06 \%$ cases (table no 04 ). In our study Kleibsiella incidence was less probably due to exclusion of diabetic patients. Zibari GB and associates in their study showed presence of gram-negative organisms in 50\% cases, gram-positive organisms in $25 \%$ patients, anaerobic organisms in $10 \%$ patients whereas no organisms found in $15 \%$ patients...[10] Giorgio et all in their study got E.Coli in $35.9 \%$, Staph in $25 \%$, Kleibsiella in $17.9 \%$, mixed in $5.1 \%$ and no organisns found in $10.3 \%$ from pus culture.[21] In a study by Azaz A Mallick and associates pus culture grew E. coli in $43 \%$ and Klebsiella in $25 \%$ of patients[6] Barrio J et al in their study showed that cultures of pus from the abscess were positive in $77.1 \%$ and Escherichia coli and Streptococcus milleri were the organisms isolated most frequently[12] Ronald Andersson and collegues showed that bacterial cultures from the hepatic abscess were positive in $75 \%$ of cases, with E.coli being the most frequently isolated organism.[22] Our study simulates results of these studies.

In our study, $50 \%$ patients need only one aspiration session, 30\% required two aspiration sessions, $18 \%$ patient need three aspiration sessions, only one patient need four time aspirations(Figure 03).Our study shows needle aspiration effective in all cases. No. of aspiration were unrelated to no or size of abscess cavity. In study done by Chu Yu S and associates the percentage of abscesses requiring one, two and three or more sessions of aspiration was $49.5 \%, 23.7 \%$ and $26.7 \%$ respectively. The overall success rate was $96.8 \%$. The success rate was unrelated to the size or number of abscess[19]. Percutaneous needle aspiration was effective in $79 \%, 88.9 \%$ and $100 \%$ cases in study by Stain SC et all[23], Rendón Unceta P et all[24], Giorgio A et al [21] respectively Rajak and colleagues (1998) reported a prospective randomized trial comparing percutaneous needle aspiration(PNA) and percutaneous catheter drainage( PCD )for amoebic and pyogenic abscesses. The trial showed a 100\% success rate for PCD and $60 \%$ for PNA with the failures successfully treated by PCD. In contrast to other studies using PNA, repeat aspirations were not performed, and this may account for the lower success rate with PNA[5].

In our study patient improved clinically within $6.24 \pm 4.02$ days (range 2 to 13 days) after first aspiration. Baek SY and collegues showed that fever had lasted from 0 to 10 days (mean, 3 days).[25] In other studies the mean time to defervescence was about four days.[21,26]. In our study total leucocyte count normalizes after mean of 7.8 \pm 5.04 days (range3 to 15 days) after therapeutic aspiration. Giorgio A et al [21] in their study showed leucocytosis resoled within 2-8 days (mean 3.8 days) .

In our study most of the patients $(50 \%)$ were discharged within 7 days. .The patients were hospitalized for mean 11 days \pm 4.56 ( range 7 to 22 days). In a study by GorgioA, Tarantio et al, patients were hospitalized 7-24 days (mean, 9 days).[6] Beak S Y et al showed the length of hospitalization varied from 5 to 42 days (mean, 22 days).[25] In study by Helen $\mathrm{M} \mathrm{H}$ et al ,overall the mean length of hospital stay for patient was 21 days.[18] Our study simulates these studies. In our study there were no reports of procedure related complications as well as no reports of recurrence on follow up.

\section{Conclusion}

In our study we found that that percutaneous needle aspiration of pyogenic liver abscesses under sonographic guidance is a safe, effective, and low-cost procedure that is acceptable to patients. This mode of treatment results in improvement in clinical features, shows reduction of size of abscess cavity and no incidences of recurrence. None of the patients in this series died. Hence, antibiotic along with image guided therapeutic needle aspiration, sometimes repeated, was found to be a valid treatment option in patient with pyogenic liver abscess So therapeutic percutaneous needle aspiration of pyogenic liver abscess (if required repeated) along with antibiotic should always be undertaken before going to more invasive modalities such as percutaneous catheter drainage or surgery.

\section{References}

[1]. Oschner A, et al,1938: Pyogenic abscess of the liver: an analysis of 47 cases with review of the literature.Am J Surg 181:177-186.

[2]. McFadzean AJ, et al, 1953: Solitary pyogenic liver abscess treated by closed aspiration and antibiotics: a report of 14 consecutive cases with recovery. Br J Surg 41:141-152.

[3]. Bertel C, 1986: Treatment of pyogenic hepatic abscess: surgical versus percutaneous drainage. Arch Surg 121:554-558.

[4]. Gerzof S, et al, 1985: Intrahepatic pyogenic abscess: treatment by percutaneous drainage. Am J Surg 149:487-494.

[5]. Rajak C, et al, 1998: Percutaneous treatment of liver abscesses: needle aspiration versus catheter drainage. AJR Am J Roentgenol 170:1035-1039

[6]. Giorgio A, Tarantino L, Mariniello N, Francica G, Scala E, Amoroso P, Nuzzo A, Rizzatto G.Pyogenic liver abscesses: 13 years of experience in percutaneous needle aspiration with US guidanceRadiology. 1995 Apr;195(1):122-4. 
[7]. Ajaz A Malik, Shams UL Bari, Khawaja Abdul Rouf, Khurshid Alam Wani 'Pyogenic liver abscess: Changing patterns in approach' World J Gastrointest Surg 2010 December 27; 2(12): 395-401

[8]. Mehta RB, Parija sc, chetty DV, et al. Management of 240 cases of liver Int abscesses.Int Surg $1986 ; 71$.

[9]. Lodhi S, Sarvari AR, Muzammil M, Salam A, Smego RA. Features distinguishing amebic from pyogenic liver abscesses: a review of 577 adult cases. Trop Med lnt Health 2004; 9: 718_23

[10]. Zibari GB, Maguire S, Aultman DF, McMillan RW, McDonald JC. Pyogenic liver abscess. Surg Infect (Larchmt). 2000;1(1):15-21

[11]. Ochsner A, DeBakey M. Amebic hepatitis and hepatic abscess (an analysis of 181 cases with review of literature) Surgery 1943; 13'.612-49'

[12]. Barrio J, Cosme A, Ojeda E, Garmendia G, Castiella A, Bujanda L, Fernández J, Arenas JI Pyogenic liver abscesses of bacterial origin. A study of 45 cases. Rev Esp Enferm Dig. 2000 Apr;92(4):232-9.

[13]. Onkar Singh, Shilpi Gupta, Sonia Moses , Devendra K. Jain: Comparative study of catheter drainage and needle aspiration in management of large liver abscesses. Indian J Gastroenterol 2009 (May-June):28(3):88-92.

[14]. Barnes PF, De Cock KM, Reynolds TN, et al: A comparison of amebic and pyogenic abscess of the liver. Medicine (Baltimore) 1987; 66:472-483.

[15]. Barbara Alkofer, Corentin Dufay, Jean Jacques Parienti, Vincent Lepennec, Sylvie Dargere, and Laurence Chiche Are Pyogenic Liver Abscesses Still a Surgical Concern? AWestern Experience HPB Surgery Volume 2012, Article ID 316013 , 7 pages doi: $10.1155 / 2012 / 316013$

[16]. .Bertel CK, van Heerden JA, Sheedy PF 2nd. Treatment of pyogenic hepatic abscesses. Surgical vs percutaneous drainage. Arch Surg. 1986 May;121(5):554-8

[17]. K C S, Sharma D Long-term follow-up of pyogenic liver abscess by ultrasound. Eur J Radiol.2010 Apr;74(1):195-8. doi:10.1016/j.ejrad.2009.01.017. Epub 2009 Feb 12

[18]. Helen M Heneghan, Nuala A Healy Sean T Martin Ronan S Ryan, Niamh Nolan, Oscar Traynor and Ronan Waldron Modern management of pyogenic hepatic abscess: a case series and review of the literature BMC Research Notes2011, 4:80 doi:10.1186/1756-0500-4

[19]. Ch Yu S, Hg Lo R, Kan PS, Metreweli C. Pyogenic liver abscess: treatment with needle aspiration. Clin Radiol. 1997 Dec;52(12):912-6.

[20]. Lo RH, Yu SC, Kan PS. Percutaneous needle aspiration in the treatment of hepatic abscess: factors influencing patients' outcome. Ann Acad Med Singapore. 1998 Mar;27(2):173-7.

[21]. Giorgio A, de Stefano G, Di Sarno A, Liorre G, Ferraioli G. Percutaneous needle aspiration of multiple pyogenic abscesses of the liver: 13-year single- center experience. AJR Am J Roentgenol. 2006 Dec;187(6):1585-90.

[22]. ROLAND ANDERSSON, LILLEMOR FORSBERG, ESBJORN HEDERSTROM, PETER HOCHBERGS and STIG BENGMARK PERCUTANEOUS MANAGEMENT OF PYOGENIC HEPATIC ABSCESSES HPB Surgery, 1990, Vol. 2, pp. $185-188$

[23]. Stain SC, Yellin AE, Donovan AJ, Brien HW. Pyogenic liver abscess. Modern treatment. Arch Surg. 1991 Aug;126(8):991-6.

[24]. Rendón Unceta P, Macías Rodríguez MA, Correro Aguilar F, Prieto García JL, Díaz García F, Martín Herrera L. Hepatic abscesses: is simple aspiration puncture with echography control an alternative to catheter drainage? Gastroenterol Hepatol. 2000 Dec;23(10):470-3.

[25]. Baek SY, Lee MG, Cho KS, Lee SC, Sung KB, Auh YH. Therapeutic percutaneous aspiration of hepatic abscesses: effectiveness in 25 patients. AJR Am J Roentgenol. 1993 Apr;160(4):799-802 